\title{
The effects of mothers' education on the nutritional outcomes of their children in Nicaragua
}

\author{
Kirk Geale \\ This manuscript was prepared under the supervision of Professor Louise Grogan, \\ Department of Economics, College of Management and Economics.
}

\begin{abstract}
Using data from the 2001 Nicaragua Demographic and Health Survey, this paper examines the relationship of a child's nutritional health outcomes relative to the completion of secondary education of their mother by measuring her child's height-for-age and weight-for-height. This study focuses on Nicaragua in particular, in contrast to other literature surveying Latin America as a whole. The persistence of malnutrition amongst the population makes Nicaragua a candidate for research in this area, especially in face of educational reforms in the country approximately 10 years prior. In this study the control variables include paternal education, geographic location, socioeconomic status, birth order, and household size; combined to help attenuate the effects of maternal education. The analysis is subdivided to examine the relation of mothers' education to health outcomes for children of each gender. It was found that maternal secondary education is significant for all scenarios with the exception of gender-separated weight-for-height, and that there is a stronger correlation between health outcomes for girls than for boys when examining maternal education.
\end{abstract}

"More education for women would be helpful for our country"21 - Michell Roman, School Teacher in San
Marcos, Nicaragua

$\mathrm{T}^{\mathrm{s}}$ he effects of education in relation to outcomes of children's health have been well documented in academic literature. This study looks at the congruency of these effects on households in Nicaragua. Two statistical methods are used in this paper to measure child health outcomes, the first of which is ordinary least-squares regressions (OLS) and the second is the probit maximum likelihood model. Both of these models measure height-forage and weight-for-height, where the independent variable recording maternal secondary education is of primary interest. The probit model measures the likelihood of an event occurring (here, the event is stunting or wasting) whereas OLS uses independent variables to explain the health outcomes of the children in the study and how those outcomes change as the explanatory variables change.

A study published in 2004 with regard to this same topic in Ethiopia found that parental education is one of the "key determinants of chronic child malnutrition in Ethiopia." "This study also found that the effect of maternal education is almost double that of paternal education and that mothers' secondary school education has a significant effect on anthropometric scores of their children when compared to uneducated mothers.

Uthman's 2009 study examined the effects of socioeconomic status on child health in Nigeria. While Uthman found that monetary wealth alone was the most prevalent contributing factor, accounting for one third of the

inequality in malnutrition, with mothers' education playing a lesser role, ${ }^{23}$ this study predicts that the effects of maternal education will be stronger than wealth. This is due in part to the high rates of return on education reported in Latin America. These two studies use many of the same variables to measure nutritional inequality, with results that are similar in direction but different in magnitude.

Nicaragua is a candidate for current research due to the persistence and prevalence of high levels of malnutrition despite educational reforms that have occurred in its recent history. The Frente Sandinista de Liberación's (Sandinista) governmental regime from 1979 to 1990 saw a radical change in educational policy. It began with the famous literacy campaign in 1980, significantly reducing the levels of illiteracy. A longitudinal study conducted on the effects of this campaign indicates that women who became literate as adults now have healthier children. ${ }^{14}$ Following the literacy initiative came an institutionalized education program in which many of the participants would be the appropriate age for inclusion in the paternal and maternal demographics in this paper. Although many of the overarching goals of the program were not achieved, the educational revolution boasts improvements such as significantly increased levels of enrollment in all educational categories (primary, secondary, tertiary) and significantly increased literacy rates. In spite of these successes, malnutrition endures in Nicaragua; Arnove and Dewees concluded this was in part due to the lack of 
time, stability, and resources in the country. ${ }^{3}$ This paper will show that although this reform was not as successful as the participants hoped it would be, it was not a misguided vision because the status of Nicaraguan children's health is in fact linked to the levels of education of their mothers.

Despite the extensive literature relating maternal education to nutritional outcomes in developing countries in general, there is still some controversy surrounding such findings. For example, Alva and Desai endeavoured to show whether or not there is in fact a strong causal relationship between maternal education and child health due to skepticism on the part of some academics. The study suggests that it is not appropriate to make a sweeping statement that mothers' education has an independently strong and positive impact on the survival of their children. However, the study also notes that in some areas of Latin America the returns to secondary education (social and private benefits) are noteworthy, and will be the focus of this study in the country of Nicaragua. ${ }^{2}$ Alva and Desai also cite a lack of proper control variables for community effects on the education coefficients, as well as controlling for income, which will also be corrected for in the models in this paper.

There are many studies that make generalized predictions about Latin America regarding maternal education and child health, which are all valid in their own right. This study will contribute to the existing literature by looking solely at evidence from Nicaragua. Using econometric techniques, this paper will explore whether maternal education is strongly related to a child's health in Nicaragua. This paper does not aim to show causality; only that a mother's education level is linked to the well being of her children. In this paper, maternal education is measured using the completion of secondary education to show whether or not she is educated, and child health is measured using height-for-age and weight-for-height comparisons. The levels of education Nicaraguan parents have on average, measured by secondary education, are quite low. Out of the 6836 observations of mothers, only $24.58 \%$ (1680 observations) have completed secondary education. Of the fathers of children measured, $20.25 \%$ (1384 observations) have been educated. ${ }^{10}$ The analysis consists of these variables as well as a variety of reasonable control variables that will be further explained. As a developing country in Central America, Nicaragua is a country with much potential. Health status is strongly linked to developing this potential, both for individuals and for the country's economic growth as a whole, and therefore it is important to understand which variables comprise the factors influencing a child's health in Nicaragua.

\section{METHODS}

The data used in this study include data from the 2001 Nicaragua Demographic and Health survey. This data set is a comprehensive questionnaire with many controls to ensure accurate representation of the population. The data in use in this study include birth order, gender, age, household size, proxies of the wealth index, an urban/rural indicator, and provincial dummy variables. Anthropometric indices including height-for-age and weight-for-age were also computed and used as the dependent variables. Anthropometry is an effective way to measure "changes in body dimensions [that] reflect[s] the overall health and welfare of individuals and populations." ${ }^{\circ}$ The two dependent variables being measured in this study, namely weight-forheight (wasting) and height-for-age (stunting) together provide an indicator of overall health status. This is because wasting measures acute under-nutrition, and is useful "when exact ages are difficult to determine" and "is appropriate for examining short-term effects." Stunting on the other hand, "is an indicator of past growth failure" and manifests from "a slowing in the growth of the fetus and the child."

The controls used in this experiment were selected because of their influence on child health outcomes and their identification in existing literature. Household size was included as a control because it suggests that the household has a certain amount of disposable income available and therefore will distribute it in limited proportions. It follows that for a fixed amount of income, a larger portion of income can be spent on the nutrition of each child, the fewer people there are in the household. This assumes of course, that the children in the household are not working and do not generate income that can benefit the household.

Birth order is included as a control variable because the amount of attention that the parents are able to pay to the wellbeing of each child must be divided between all of the existing children. The more siblings a child has, the less time the parents have to monitor and engage in the child's nutrition levels. Also due to the phenomenon of "unwanted children," the parents may invest more in children higher in the birth order with the expectation that these resource allocations may not be divided between other unexpected children they are not yet aware of. Birth control is not a well understood and utilized method of family planning and so birth order may have a negative impact on the well being of children with a lower birth order. Parents are not necessarily actively discriminating amongst their children; they may be unable to reallocate resources over the long run to offset the advantages of children with higher birth order. ${ }^{16}$

The wealth index is comprised of a group of variables that record whether a family owns a toilet, telephone, bicycle, car, truck, electricity, and a floor in the house. As a whole, this is a necessary control because the higher the household's wealth, more income the family is able to spend on health related purchases, whether it be nutritional food or doctor access. These factors clearly affect the parents' ability to properly feed their children. The dummy variables for the wealth index proxies are constructed in a way that records a 1 if the variable is "true" for the family. This can be understood in two ways: 1 if the family has a car, 0 if they do 
not. In another example, the variable is recorded as 1 if the family has "nofloor" (it is true that they have no floor), and 0 if they do have a floor.

Urban areas in Nicaragua, as in many other countries, differ greatly in their access to a variety of products and services, one of which is food and the quality of that food. Because infrastructure in developing countries is usually underdeveloped, there is a shortage of sustenance required for proper nutrition and information on proper nutritional practices that families can partake in. During a visit to a rural area outside of San Marcos for example, I learned that women generally believe that sugar is needed to keep the fluid around the brain healthy. As a result, children from a very young age are fed excessive amounts of sugar. The educational infrastructure in rural areas has been well documented to be inferior of that in urban centers. ${ }^{17}$

Dummy variables for each of the country's 19 provinces were included in order to take into account differing geographic advantages or disadvantages. As an example, areas that farm particular crops that do not add to nutrition of the local citizens will not have the benefits realized by an area that grows nutritious crops. The regional variables help control for the verity that "poorer children are more likely to live in regions with disadvantageous characteristics." ${ }^{\text {23 }}$ They also help to control for the community effects that can be present, for example spillover in a province with a university, or the presence of a health focused NGO. There are many community effects, and the provincial dummy variable will help to control for these as well as the geographic effects. For example, "educated mothers tend to live in more economically developed areas" and areas that are rich enough to have schools are also probably rich enough to have medical facilities. ${ }^{2}$

When examining coefficients in this paper, it must be kept in mind that the dependent variables measuring the $\mathrm{z}$ scores $^{\mathrm{a}}$ for height-for age and weight-for-height have been limited to $\mathrm{z}$-scores with standard deviations below 5, to eliminate extreme values in the data sets, which are likely incorrect.

The two anthropometric measures, height-for-age and weight-for-height, were created from the data in the 2001 Nicaragua Demographic and Health Survey in conjunction with the 2000 United States CDC growth charts. The CDC Growth Chart is one of two standard measures, and was chosen over the 1990 UK British growth charts due to geographic proximity, and because the surveys are only two years apart (CDC 2000 Growth Charts and 2001 Nicaragua Health and Demographic Survey). Because gender is included within the z-scores for the height-for-age and weight-for-height variables, it does not appear explicitly as a control variable in any of the specifications. In the creation of the z-scores for the height-for-age and weight-for-height anthropometric measures, there are a variety of variables included. One of these is gender; the others are weight, height, age, and the standards from the CDC growth charts.

The regressions presented in this paper show the independent variables affecting height-for-age and weightfor-height. There are 19 proxy provincial variables present, which will be represented in the regression simply as "PROV," with the coefficient $\beta_{7 \mathrm{j}}$ where $\mathrm{j}$ is each individual province $(1 \leq \mathrm{j} \leq 19)$. This method has also been applied to the proxies of the wealth index, which will appear together as "WEALTH" where the coefficient is $\beta_{6 \mathrm{i}}$ where $\mathrm{i}$ is each wealth index proxy $(1 \leq \mathrm{j} \leq 7)$. These proxies will only be broken out when there is a specific reason for identifying an individual component.

The measures of height-for-age and weight-for-height are z-scores, are measured as such in the first two OLS regressions. In the probit regressions, the z-scores are represented by binary variables in which 1 represents a zscore from -5 to -2 (stunted or wasted), and 0 represents a zscore from -2 to 5 (healthy). This conversion was applied to both the height-for-age and weight-for-height variables to be used in the probit model.

\section{ANALYSIS}

\section{Ordinary Least Squares (OLS) Regression}

The following equation shows the general form of OLS regressions:

$$
\text { [1] } \mathrm{Y}=\beta_{0}+\beta_{1} X_{1 i}+\beta_{2} X_{2 i}+\ldots+\beta_{K} X_{K i}+\varepsilon
$$

Where $\mathrm{Y}$ is the dependent variable, $\mathrm{X}$ is an independent variable, and $\beta$ is the magnitude of the effect of $\mathrm{X}$ on $\mathrm{Y}$. The following specification uses this model to measure the $\mathrm{z}$ scores of height-for-age (Z_HFA) with the aforementioned independent variables.

$$
\begin{aligned}
\text { [2] } & Z_{-} \text {HFA }=\beta_{1}\left(\mathrm{~F}_{-} \text {EDU }\right)+\beta_{2}\left(\mathrm{M}_{-} \text {EDU }\right)+ \\
& \beta_{3}\left(\mathrm{BIRTH}_{-} \mathrm{ORDER}\right)+\beta_{4}(\mathrm{HHSIZE})+ \\
& \mathrm{B}_{5}(\mathrm{URBAN})+\beta_{6 \mathrm{i}}\left(\mathrm{WEALTH}_{\mathrm{i}}\right)+ \\
& \beta_{7 \mathrm{j}}\left(\text { PROV }_{\mathrm{i}}\right)+\varepsilon
\end{aligned}
$$

Table 1 illustrates the coefficients on each independent variable.

The results of the regression show that mothers' education (F_EDU) is statistically significant. ${ }^{\text {b }}$ This was expected in the regression analysis, as was the significant effect of fathers' education (M_EDU) on child health. The coefficients on the maternal and paternal variables are quite different however; maternal education has more than twice the effect on child health outcomes when compared to paternal education. 
Table 1: Height-for-age OLS Regression Coefficients and Standard Errors $\mathrm{c}$

\begin{tabular}{|l|r|r|}
\hline Variable & Coefficient $(\boldsymbol{\beta})$ & (Standard Errors) \\
\hline $\begin{array}{l}\text { Mother has } \\
\text { secondary education } \\
\text { (F_EDU) }\end{array}$ & 0.3501295 & $(.0564483)^{*}$ \\
\hline $\begin{array}{l}\text { Father has secondary } \\
\text { education (M_EDU) }\end{array}$ & 0.141581 & $(.0570494)^{\star *}$ \\
\hline $\begin{array}{l}\text { Birth Order of child } \\
\text { (BIRTH_ORDER) }\end{array}$ & -0.0085099 & -0.0086572 \\
\hline $\begin{array}{l}\text { House hold size } \\
\text { (HHSIZE) }\end{array}$ & -0.0415776 & $(.0066239)^{*}$ \\
\hline $\begin{array}{l}\text { Household in urban } \\
\text { location (URBAN) }\end{array}$ & -0.1487266 & $(.0561765)^{\star}$ \\
\hline
\end{tabular}

\begin{tabular}{|l|r|r|}
\hline $\begin{array}{l}\text { Wealth Index } \\
\text { Proxy }\end{array}$ & Coefficient $(\boldsymbol{\beta})$ & (Standard Errors) \\
\hline No toilet & -0.8667101 & -0.5262568 \\
\hline Telephone & 0.4113326 & $(.1090747)^{\star}$ \\
\hline Bicycle & 0.0913718 & -0.0578393 \\
\hline Moto & -0.1650091 & -0.154491 \\
\hline Truck & 0.2380628 & $(.0917056)^{*}$ \\
\hline Electricity & 0.2914308 & $(.0584439)^{*}$ \\
\hline No Floor & -0.2327386 & $(.051536)^{*}$ \\
\hline
\end{tabular}

* Significant at $\mathrm{p}<1 \%$

** Significant at $\mathrm{p}<5 \%$

$* * *$ Significant at $\mathrm{p}<10 \%$

Within the provincial dummy variables, there was a considerable range of statistical significance as well as in the magnitude of coefficients. The coefficients ranged from 0.24 to 0.79 . Generally, the stronger coefficients pertained to variables that were statistically different from 0 . Both household size and birth order were significant, affecting the measured $z$-score at a rate of -0.0416 and -0.0085 respectively.

In the second regression measuring weight-for-height $\left(\mathrm{Z} \_\mathrm{WFH}\right)$, the results were quite different. The specification for this measurement includes the same variables measured against weight-for-height:

$$
\begin{aligned}
& {[3] \mathrm{Z}_{-} \mathrm{WFH}=\beta_{1}\left(\mathrm{~F}_{-} \mathrm{EDU}\right)+\beta_{2}\left(\mathrm{M} \_ \text {EDU }\right)+} \\
& \beta_{3}\left(\mathrm{BIRTH}{ }_{-} \mathrm{ORDER}\right)+\beta_{4}(\mathrm{HHSIZE})+ \\
& \mathrm{B}_{5}(\mathrm{URBAN})+\beta_{6 \mathrm{i}}(\mathrm{WEALTH})+\beta_{7 \mathrm{j}}(\mathrm{PROV}) \\
& +\varepsilon
\end{aligned}
$$

From Table 2 it is easy to see the statistical insignificance of almost all of the regressed variables. The only one with statistical significance is the variable of most importance to this study, maternal education.
Table 2: Weight-for-height OLS Regression Coefficients and Standard Errors ${ }^{\mathrm{d}}$

\begin{tabular}{|l|r|r|}
\hline Variable & Coefficient $(\boldsymbol{\beta})$ & (Standard Errors) \\
\hline $\begin{array}{l}\text { Mother has } \\
\text { secondary education } \\
\text { (F_EDU) }\end{array}$ & 0.1031464 & $(.0509989)^{\star *}$ \\
\hline $\begin{array}{l}\text { Father has secondary } \\
\text { education (M_EDU) }\end{array}$ & 0.0101814 & -0.0517632 \\
\hline $\begin{array}{l}\text { Birth Order of child } \\
\text { (BIRTH_ORDER) }\end{array}$ & -0.006691 & -0.0076056 \\
\hline $\begin{array}{l}\text { House hold size } \\
\text { (HHSIZE) }\end{array}$ & 0.000366 & -0.0061059 \\
\hline $\begin{array}{l}\text { Household in urban } \\
\text { location (URBAN) }\end{array}$ & 0.0759043 & -0.0508998 \\
\hline
\end{tabular}

* Significant at $\mathrm{p}<1 \%$

** Significant at $\mathrm{p}<5 \%$

$* * *$ Significant at $\mathrm{p}<10 \%$

A second set of regressions was run on both height-forage and weight-for-height after disaggregating male and female children. All of the independent variables were the same, in order to determine whether maternal education has a different effect on health outcomes of her children based on their gender. The results in Table 3 illustrate the differences between the four combinations of gender and anthropometric measure.

The effect of maternal secondary education on both male and female children found earlier in the Table 1 regression against height-for-age was reported as .3501295 $(1 \% \mathrm{CI})$ and in the Table 2 regression against the $\mathrm{z}$-score for weight-for-height maternal education was reported as .1031464 (5\% CI). However, due to the overlapping standard error of maternal education variable between genderseparated OLS specifications, a Chow test was conducted (see Appendix 5) with the null hypothesis that the coefficients are simultaneously equal to zero. $\mathrm{P}>\mathrm{F}$ was reported as zero for both the height-for-age and weight-forheight regressions, indicating that the coefficients are comparable across specifications. It can then be concluded that daughters' nutritional outcomes are more strongly related to mothers' secondary educational attainment than sons' in terms of height-for-age, and sons' outcomes are slightly more responsive to maternal secondary educational attainment than daughters' outcomes in terms of weight-forheight.

It was anticipated that there would be collinearity between certain variables, particularly mothers' education and fathers' education. At $36 \%$, the correlation was lower than expected. Due to the importance of considering paternal education in a theoretically sound specification, it was decided to maintain the paternal education variable for inclusion in the specifications. Variance inflation factors (VIF's) were measured using 5 as an acceptable maximum to check for multicollinearity, and none of the VIF's were 
Table 3: Height-for-age and weight-for-height OLS Regressions Gender Separated Coefficients and Standard Errors

\begin{tabular}{|l|l|r|r|}
\hline $\begin{array}{l}\text { Gen- } \\
\text { der }\end{array}$ & Dependent Variable & $\begin{array}{r}\text { Coefficient } \\
(\boldsymbol{\beta})\end{array}$ & $\begin{array}{r}\text { (Standard } \\
\text { Errors) }\end{array}$ \\
\hline \multirow{2}{*}{ Male } & z-score for height-for-age & 0.3011998 & $(.0744169)^{*}$ \\
\cline { 2 - 4 } & $\begin{array}{l}\text { z-score for weight-for- } \\
\text { height }\end{array}$ & 0.1145934 & -0.0720528 \\
\hline \multirow{2}{*}{ Female } & z-score for height-for-age & 0.3775208 & $(.0814193)^{*}$ \\
\cline { 2 - 4 } & $\begin{array}{l}\text { z-score for weight-for- } \\
\text { height }\end{array}$ & 0.0982681 & -0.0697703 \\
\hline
\end{tabular}

$*$ Significant at $\mathrm{p}<1 \%$

** Significant at $\mathrm{p}<5 \%$

$* * *$ Significant at $\mathrm{p}<10 \%$

Table 4: Tests for Heteroskedasticity for the weight-forheight OLS Regression

\begin{tabular}{|l|l|r|r|}
\hline \multirow{3}{*}{ a) } & Chi' $^{2}$ & & 7.51 \\
\cline { 2 - 2 } & Prob > Chi & & \\
\cline { 4 - 4 } & Source & $\mathrm{Chi}^{2}$ & $\mathrm{P}>\mathrm{Chi}^{2}$ \\
\hline \multirow{3}{*}{ b) } & Heteroskedasticity & 337.52 & 0.0061 \\
\cline { 2 - 4 } & Skewness & 56.38 & 0.0022 \\
\cline { 2 - 4 } & Kurtosis & 16.9 & 0 \\
\hline
\end{tabular}

$\mathrm{H}_{0}$ is the null hypothesis that residuals are homoskedastic.

a) Cook/Weisberg test for heteroskedasticity

b) Cameron and Trivedi decomposition of the IM test for

the $\mathrm{z}_{-}$whf regression: an information matrix of $\mathrm{Chi}^{2}$ probabilities of violations against assumptions of the error term for the $z_{-} h f a$ regression

greater than 5. In fact, the highest VIF is 2.90, and the mean was 1.72 . It should also be noted that the highest 11 VIF's were provincial dummy variables.

The very low $\mathrm{R}$ squared $^{\mathrm{f}}$ measure of goodness of fit points toward the possibility of omitted variables, and therefore impure heteroskedasticity. ${ }^{\mathrm{g}}$ To test this hypothesis, the Breusch-Pagan/Cook-Weisberg test was employed on the regression in Table 4.a against the z-score for height-for-age, and it was found that there was in fact a high probability of heteroskedasticity.

From the results in Table 4.a it was concluded that robust regressions needed to be used. Also, by using Cameron and Trivedi's decomposition of assumptions on the regression errors, the information matrix in Table 4.b confirms that there are violations on these standard assumptions of least square regressions. To rectify this, the regression was performed using robust analysis, resulting in the $t$ statistics recorded in Tables 1, 2, and 3. Adding robustness to the analysis did not significantly change the t-statistics of any of the independent variables.

In the regression against the z-score for weight-for-height, similar tests for heteroskedasticity were performed, with the following results.
Table 5: Tests for Heteroskedasticity for the weight-for-height OLS Regression

\begin{tabular}{|l|l|r|r|}
\hline \multirow{3}{*}{ a) } & Chi $^{2}$ & & 0.22 \\
\cline { 2 - 2 } & Prob > Chi $^{2}$ & & 0.6367 \\
\cline { 2 - 2 } & Source & $\mathrm{Chi}^{2}$ & $\mathrm{P}>\mathrm{Chi}^{2}$ \\
\hline \multirow{2}{*}{ b) } & Heteroskedasticity & 315.94 & 0.0192 \\
\cline { 2 - 2 } & Skewness & 32.06 & 0.2720 \\
\cline { 2 - 2 } & Kurtosis & 55.25 & 0 \\
\hline
\end{tabular}

$\mathrm{H}_{0}$ is the null hypothesis that residuals are homoskedastic.

a) Cook/Weisberg test for heteroskedasticity

b) Cameron and Trivedi decomposition of the IM test for the z_whf regression: an information matrix of $\mathrm{Chi}^{2}$ probabilities of violations against assumptions of the error term for the $z_{-} w f h$ regression

Tables 5.a and 5.b together reveal conflicting conclusions: from the Cook-Weisburg test, the null hypothesis of homoskedasticity would not be rejected, yet the Cameron and Trivedi decomposition would suggest the regression suffers from heteroskedasticity. In order to err on the side of caution, robust regressions were also used for the weight-for-height regression. With similar results to the height-for-age regression, the robust analysis changed the tscore of any given variable by very little, or resulted in no change at all. No variables' significance at the 95 percent confidence interval was affected. Checking for multicollinearity by comparing VIF's in this regression is the same as for the height-for-age regression, because the independent control variables are the same in both analyses.

\section{Binomial Probit Model}

The maximum-likelihood probit model is used to determine the likelihood of a child being stunted or wasted using the same variables as in the OLS the regressions. The model takes the form:

$$
P_{i}=\frac{1}{\sqrt{2 \pi}} \int_{-\infty}^{Z_{i}} e^{-s^{2} / 2} d s
$$

Where $P_{i}$ is the probability that the child is 2 standard deviations or below, $s$ is a standard normal variable, and $Z_{\mathrm{i}}$ is the sum of the individual components of the regression.

The resulting coefficient of mothers' education is 0.3386 , with statistical significance. The interpretation of this negative coefficient is related to the construction of the binary independent variable: If the child is stunted the independent variable is 1 , if not, 0 . Therefore mothers' education significantly reduces the probability of a child being stunted. Paternal education is also negatively correlated to the probability of stunting, and the wealth index behaves in a similar manner. Higher birth order also contributes to the likelihood of stunting, as does an urban location. As expected in this regression, the constant term is 


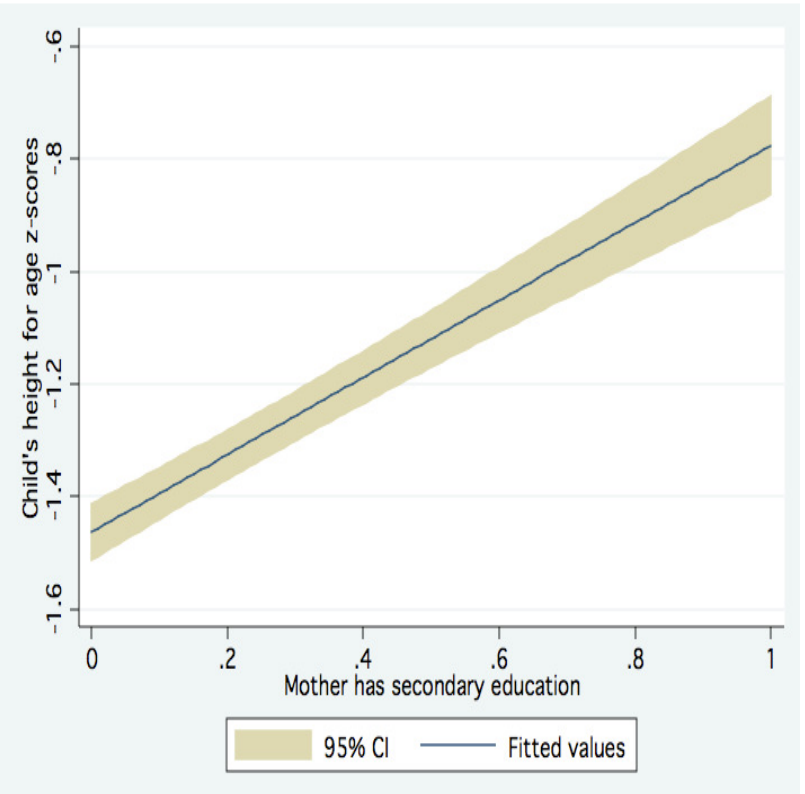

Figure 1: Fitted Values for Mother's Education on Child's height-for-age z-scores

statistically significant with a coefficient of -0.5233 . The reason for this is the same as in the least-squares regression; the lower health status in Nicaragua in comparison to the United States.

The probit analysis measuring the probability of weight-for-height exhibits the same low level of statistical significance as the least-squares regression. The statistical significance of maternal education is low, and clearly outside the $95 \%$ significance level. This implies that the variable does not affect the probability of being 2 standard deviations below the mean U.S. weight-for-height. In fact, the only significant variables are 2 wealth index proxies and 2 provincial dummy variables. The constant term is significant, with a coefficient of -1.6860 , which is consistent with the reasons previously mentioned. The results of the two probit specifications are displayed in Appendices 3 and 4.

\section{DISCUSSION}

It is interesting that in both the probit and OLS regression using weight-for-height the urban location of a household contributes to lower values of the anthropometric measures. A possible explanation for this outcome is because a large portion of rural inhabitants farm, and therefore have access to a primary source of food.

Comparing the two least-squares regressions of heightfor-age and weight-for-height produces some interesting results. Maternal education is significant for both measures, and is in fact the only variable that spans the two regressions in terms of significance. As mentioned in the introduction, height-for-age is a longer term measure of child health than weight-for-height, which has a tendency to be a short-term measure. Further, phenomenon emphasizes the value of

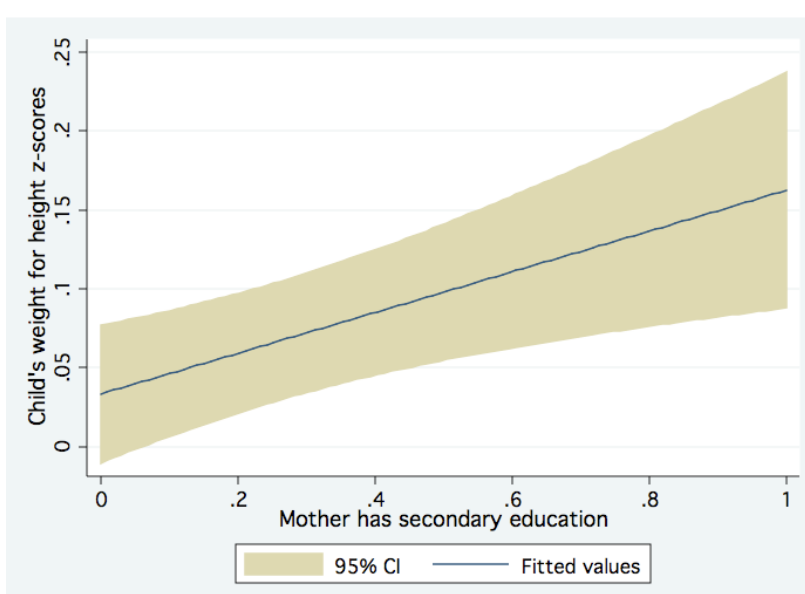

Figure 2: Fitted Values for Mother's Education on Child's weight-for-height $z$-scores

mothers' education, by showing its importance in both of these circumstances. Maternal education in this model is the only predictor of both short-term and long-term child health, to the exclusion of all other independent variables.

Maternal education exhibits clear correlation with child health as was hypothesized, consistent with generalized findings in past research. This trend is exhibited in Figure 1, showing the correlation of mothers' secondary education and $z$-scores for children's height-for-age with a $95 \%$ confidence interval.

It is easy to see from Figure 1 the positive relationship between maternal education and height-for-age in Nicaragua. The regression demonstrated the statistical significance of these findings. In the weight-for-height correlation the values of maternal education fit the z-scores as shown in Figure 2. A comparison of these graphs visually depicts the larger variability of the maternal education variable: $\mathrm{P}>|\mathrm{t}|=0.000$ for height-for-age whereas $\mathrm{P}>|\mathrm{t}|=0.043$ for weight-forheight. This simply means that maternal education predicts child health outcomes measured by stunting more accurately than for wasting because the regression for stunting has a smaller confidence interval. It was also expected that the strength of the maternal education variable would be higher if there were more detailed information regarding the quality of education, as opposed to the measurement used here which is simply enrollment. Educational quality is difficult to quantify, but it is logical to assume that with a higher quality of education, the magnitude of maternal education would be higher.

The constant terms in the two robust regression analyses were expected to be negative. This is because, as a developing country, it is expected that Nicaragua has a lower average nutritional attainment than the standard against which it is measured, in this case U.S. children. The constant term is near what was expected for the height-for-age specification, with a value of -1.4. This implies that the average child in this sample population is 1.4 deviations below that of comparable children in the sample U.S. 
population (in which the mean is 0 ). However, the constant term in the weight-for-height regression is reported at 0.03 . The statistical insignificance of this intercept term $(\mathrm{P}=0.754$ $>|t|)$ suggests that variation from this trend is likely and may still be less than 0. Although there is insufficient evidence to make this conclusion, it is suspected that it is true and the constant term is in fact less than 0 . The reason for the discrepancy between constant terms in both the least-square regression and probit models of weight-for-height and height-for-age is simply that the mean of the z-score for the height-for-age regression is -1.2957 and the mean of the $\mathrm{z}$ score for the weight-for-height regression is -0.0662 . Higher means for height-for-age are present in all four models presented in this paper.

Difference in ethnic demographics in Nicaragua likely plays a role in controlling for the effects influencing the anthropometric measures of Nicaraguan children. The largest demographic is $69 \%$ mezito, indicating room for variety in ethnicity. ${ }^{24}$ This study has not explicitly controlled for race or ethnicity, which are thought of as "important...individuallevel determinants of child health." ${ }^{2}$ However, the provincial variables are expected to adequately control for this, as race varies with geography. ${ }^{7}$

An influence upon health statuses in Nicaragua that has not been accounted for in the models presented in this paper is political affiliation. Inhabitants of a given area are inclined towards a particular political party and when that particular party is in power, political support is an advantage due to the distribution of government food. This is true in other arenas as well; supporters of the political group in power gain other general advantages that influence health. However, from direct observation it is common for entire geographic areas to be inclined towards the same party, so it is likely that the geographic variables picked up a large portion of this effect. If a statistic recording political affiliation were available with the other survey information, in theory it would help explain the overall fit of the model and improve the accuracy of measurement in these specifications.

The very low value of the $\mathrm{R}$ squared goodness of fit in the least squares regressions $(12.35 \%$ for height-for-age and $2.53 \%$ for weight-for-age) was surprising. It is likely caused in some part by specification errors, possibly due to the racial and ethnic variables or political affiliation that have already been discussed. In the context of this model however, the way $\mathrm{R}$ squared is measured will inevitably be lower than desired due to the nature of the variables. For example, if a family does not have a truck, there is still a possibility that the mother has secondary education. Although they both contribute to higher anthropometric z-scores, they are not mutually exclusive. This principle likely affects a variety of variables. That being said, however, the almost nonexistent value of the $\mathrm{R}$ squared suggests there are one or more significant factors missing in the regressions.

The pseudo $\mathrm{R}$ squared reported in the probit models are not of great concern, except in the context of the evaluation the two models against each other. The modeling software STATA uses McFadden's pseudo R squared measure that "without context has little meaning.", In comparing the two models however, the height-for-age probit is a better fit than the weight-for-height model, as was the trend with the OLS regressions.

The single proxy for the wealth index that spans both OLS regressions in terms of $95 \%$ significance is the variable for the truck ownership. This is not surprising as it is the highest socioeconomic indicator in the wealth proxies. This simply suggests that wealth is correlated with the health outcomes of the children in the family, and supports previous research that led to the inclusion of these control variables in the specifications in this paper. The dummy variables for provinces $7,10,11$, and 19 were also significant at $95 \%$ in the two main OLS regressions, suggesting that these regions influence child health outcomes. However, the discrepancies between positive and negative coefficients influencing the two health measures portray ambiguous results.

\section{Conclusions}

Maternal education has a significant effect on the health outcomes of a mother's male and female children when measured by both height-for-age and weight-for-height. However, the relation of maternal secondary education on female children's height-for-age is larger than male heightfor-age. The probit model reveals that maternal secondary education is significantly negatively correlated to the probability of a child being stunted, but not significantly related to the wasting of her child. This study reveals that in Nicaragua, a mother's completion of secondary education correlates positively with higher levels of child health.

\section{ACKNOWLEDGMENTS}

The motivation for this research was driven by a volunteer trip to a rural region of Nicaragua called San Marcos. During my trip I lived, worked, and got to know the people in the community near the Skylark Center, all of whom contributed to a very inspirational month long journey. Thanks are due to Karl and Heather Murch, Michell Roman, Joni, and Elvin for their help in the creation of this paper - and of course to my supervisor, Professor Louise Grogan.

\section{ENDNOTES}

${ }^{\mathrm{a}} \mathrm{A} \mathrm{z}$-score is the number of standard deviations a set of data is away from the mean (average). The standard deviation shows how much variation there is between an observation and the mean.

${ }^{\mathrm{b}}$ Significant within the confidence interval expressed in the Table, that is, there is an $x \%$ chance the variable's 
coefficient will be outside the value of $\beta \pm$ the corresponding standard error

${ }^{\mathrm{c}}$ The other variables explaining the model are the 19 provincial variables. The full specification can be seen in Appendix 1.

d The additional explanatory variables are the 19 provincial variables, as well as the wealth index proxies (the same as are listed in Table 1). The full specification can be seen in Appendix 2.

${ }^{\mathrm{e}}$ A violation of the OLS assumptions where two explanatory variables are correlated

${ }^{\mathrm{f}} \mathrm{R}$ squared is a measurement of the overall fit of the specification, that is the variability of the dependent variable that can be accounted for by the independent variables ${ }^{g}$ A violation of the OLS assumptions where the variance of the error term is not consistent

\section{REFERENCES}

1. Alderman, Harold; Luc, Christiaensen. (2004). Child Malnutrition in Ethiopia: Can Maternal Knowledge Augment the Role of Income? Economic Development and Cultural Change, 52, 287-312.

2. Alva, Soumya; Desai, Sonalde. (1998). Maternal Education and Child Health: Is There a Strong Causal Relationship? Demography, 35(1), 71-81.

3. Arnove, Robert; Dewees, Anthony. (1991). Education and Revolutionary Transformation in Nicaragua, 19791990. Comparative Education Review, 35(1), 92-109.

4. Bannon, Ian; Marques, José. (2003). Central America: Education Reform in a Post-Conflict Setting, Opportunities ad Challenges. CPR Working Papers: Social Development Department, Paper No. 4, 1-25.

5. CARMEN Country Profiles. (2006). WHO Global InfoBase Online. Retrieved from https://apps.who.int/infobase/report.aspx?rid=111\&iso=N IC\&goButton=Go.

6. Cataldo, M., Filipp, L., Finney, J., Kidwell, S., Mellits, D., Quaskey, S., ... Starfield, B. (1993). Determinants of Children's Health Care Use: An Investigation of Psychological Factors. Medical Care, 31(9), 767-783.

7. Charles, Camille Z. (2003). The Dynamics of Racial Residential Segregation. Annual Review of Sociology, 29, 167-207.

8. Cogill, Bruce. (2001). Anthropometric Indicators Measurement Guide. Food and Nutritional Assistance Project. (Academy for Educational Development). Washington, DC, 8-96.

9. Conger, Rand; Lorenz, Frederick; Elder, Glen; Wickrama, K. (1998). Parental Education and Adolescent Self-Reported Physical Health. Journal of Marriage and Family, 60(4), 967-978.
10. Demographic and Health Surveys. Nicaragua: Standard DHS, 2001 [Stata System Files]. Retrieved from http://www.measuredhs.com/accesssurveys/.

11. Esquivel, Yannete; Gurdian, Nidia Veronica; Handa, Sudhanshu; Lopez, Blancadilia; Pineda, Heiling; Regalia, Ferdinando. (2009). Non-formal basic education as a development priority: Evidence from Nicaragua. Economics of Education Review, 28, 512-522.

12. Fuller, Bruce; Rivarola, Magdalena. (1998). Nicaragua's Experiment to Decentralize Schools: Views of Parents, Teachers, and Directors. Impact Evaluation of Education Reforms: Working Paper No. 5, 1-87.

13. Glewwe, Paul. (1998). Why does Mother's Schooling Raise Child Health in Developing Countries? Evidence from Morocco. The Journal of Human Resources, 34(1), 124-159.

14. Hanemann, Ulrike. (2006). Nicaragua's Literacy Campaign. Paper commissioned for the EFA Global Monitoring Report 2006, Literacy for Life, 1-13.

15. Henriques, Maria-Helena; Thomas, Duncan; Strauss, John. (1991). How Does Mother's Education Affect Child Height? The Journal of Human Resources, 26(2) 183-211.

16. Horton, Susan. (1988). Birth Order and Child Nutritional Status: Evidence from the Philippines. Economic Development and Social Change, 36(2), 341-354.

17. Kahn, Mahmood. (2001). Rural Poverty in Developing Countries: Implications for Public Policy. International Monetary Fund: Economic Issues, 26. Retrieved from http://www.imf.org/external/pubs/ft/issues/issues26/index .htm.

18. Murch, Karl, personal communications, May, 2009.

19. Pefia, Rodolfo; Persson, Lars-Ake. (2000). The Effect of Poverty, Social Inequity, and Maternal Education on Infant Mortality in Nicaragua, 1988-1993. American Journal of Public Health, 90(1), 64-69.

20. Riding, Alan. (1980, June 3). Nicaragua Drafts the Young for a War on Illiteracy. New York Times, p. A2.

21. Roman, Michell, personal communications, May, 2009.

22. UCLA: Academic Technology Services, Statistical Consulting Group. (2006). FAQ: What are pseudo Rsquareds? Retrieved from http://www.ats.ucla.edu/stat/mult_pkg/faq/general/Psued o_RSquareds.htm.

23. Uthman, Olalekan. (2009). Decomposing Socioeconomic inequality in childhood malnutrition in Nigeria. Maternal and Child Nutrition, 5, 358-367.

24. The World Factbook. (2009). Central America and Caribbean: Nicaragua. Central Intelligence Agency. Retrieved from https://www.cia.gov/library/publications/the-worldfactbook/geos/nu.html. 